Original Research Paper

\title{
Building Design Rule for Glass Structures by Persian Curve
}

\author{
${ }^{1}$ Abdolrasoul Ranjbaran, ${ }^{2}$ Mohammad Ranjbaran and ${ }^{3}$ Fatema Ranjbaran \\ ${ }^{1}$ Department of Civil and Environmental Engineering, Shiraz University, Shiraz, Iran \\ ${ }^{2}$ Department of Chemical Engineering, Yasuj University, Yasuj, Iran \\ ${ }^{3}$ Department of Mechanical Engineering, Shiraz University, Shiraz, Iran
}

\begin{abstract}
Article history
Received: $19-10-2020$

Revised: 15-01-2021

Accepted: 16-01-2021

Corresponding Author:

Abdolrasoul Ranjbaran

Department of Civil and

Environmental Engineering,

Shiraz University, Shiraz, Iran

Email: ranjbarn@shirazu.ac.ir

aranjbaran@yahoo.com
\end{abstract}

\begin{abstract}
Glass is being increasingly used as a structural material. Its favorable aesthetic qualities have made it popular with modern designers. Recently glass is used for major structural elements such as beams and columns in modern and innovative architectural applications. High slenderness ratios and brittle behavior in tension contribute to the complexity of stability and ultimate strength analysis of glass structures. Moreover the available design curves and methods of ultimate strength analysis of glass structure contain epistemic uncertainty, therefore are not reliable. In this study, based on logical reasoning, concise mathematics and reliable data, a reliable method called the change of state philosophy is developed and expressed in the Persian curve. The Persian curve is used for reliable analysis of glass structures. The validity of the work is verified via its sound basic formulation and comparison of the results with those of the others in the literature.
\end{abstract}

Keywords: Change of State Philosophy, Persian Curves, Glass Elements, Reliable Data, Epistemic Uncertainty, Design Curve, Buckling

\section{Introduction}

Glass is being increasingly used as a structural material in particular its favorable aesthetic qualities have made it popular with modern designers. The most recent developments have seen glass being used as major structural elements such as beams and columns. From the engineering viewpoint these new applications presents a series of design problems which need to be addressed before a coherent and safe design philosophy can be achieved. Porter (2011) used a fracture mechanics approach for remedy. Feldmann and Longosch (2010) focused on the results of buckling with monolithic sections of heat strengthened and tempered glass, giving buckling curves proposed by derivations and experiments. The buckling of laminated glass composite beams in compression is investigated in (Amadio and Bedon, 2011). They used a simple analytical model developed on the basis of Newmark's theory of composite beams with deformable connections. Finally, simple design criteria have been proposed to prevent buckling failure. Ouwerkerk (2011) focused on further knowledge and understanding of the structural aspects specifically related to structural glass columns and, on the basis of these findings, to design glass column as structural element in a pavilion. An exploratory study to the design aspects of glass columns was performed by doing experiments. The load carrying behavior of in plane compress and in plane shear laminated glass elements was investigated by (Amadio and Bedon, 2012; 2013) respectively. Bedon and Amadio (2015), proposed a Eurocode-based approach for buckling verification of glass columns and beams. Based on experimental and numerical results from the literature, buckling curves are proposed for laminated glass beams and columns composed of up to three glass layers. The stability of laminated glass beams and columns up to five layers, subjected to compressive load, mid-span loads, uniformly distributed loads, four-point bending and pure bending or torsion, was investigated by (Costa MSLM, 2015). The shear buckling response and actual resistance of structural glass walls with non-ideal restraints has been assessed by means of extended finite element method in (Bedon and Amadio, 2017). Bedon and Amadio (2017), proposed and analytical formulation for the resistance verification of a structural element under ultimate state variable loads. The method is assessed toward three existing analytical formulations. Evaluation of lateral-torsional buckling resistance and actual behavior of the beams due to absence of standards for design of glass load-bearing structures is done by (Pešek and Melcher, 2018). Experimental results were 
compared with lateral torsional buckling resistance calculated according to the buckling curve approach. Analysis and design of glass structural members is an active area of study in this days (Bedon and Amadio, 2018; Bedon, 2019; Bedon et al., 2019; Koca, 2019; Santo et al., 2020).

Current state of the art of the methods for analysis of structural glass members, is based on the so called PerryRobertson method, in which the ultimate strength is obtained via analysis of a member with initial lateral displacement. Selection of the shape and the value of initial displacement along with using the linear governing equation, introduced epistemic (lack of knowledge) uncertainty to the work. The epistemic uncertainty can only be removed by change of philosophy behind the work.

The current authors research team detected the need for remedy and after extensive research (Ranjbaran et al., 2008; Ranjbaran, 2010; Ranjbaran et al., 2011; Ranjbaran, 2012a-b; 2013; Ranjbaran and Rousta, 2013a-b; Ranjbaran et al., 2013a-b; Ranjbaran and Ranjbaran, 2014; Ranjbaran, 2014; 2015; 2016; Ranjbaran and Ranjbaran, 2016; 2017a-c; 2018; Hosseini et al., 2018; Amirian and Ranjbaran, 2020; Baharvand and Ranjbaran, 2020a-b; Ranjbaran et al., 2020a-d), in the last two decades, proposed the Change of State Philosophy (CSP) which expressed in the Persian Curves (PC) (Ranjbaran et al., 2020a). The aim of the presented paper is to derive and validate the (PC) and then apply it for analysis of structural glass members as follows.

\section{Basic Formulation}

In this section, the basic formulation for the change of state philosophy via a sound logical basis, is developed. All parameters are managed to be nonnegative. The traditional formulations in the academic universe are divided into the stiffness method and the flexibility method. The stiffness method, is based on the change of a decreasing system parameter, called stiffness, as shown in Fig. 1. While the flexibility method makes use of flexibility (inverse of stiffness as an increasing parameter) as shown in Fig. 2. Near the end of the phenomenon, the stiffness become very small and the flexibility become very large and hence introduce uncertainty into the work. As shown in Fig. 3 near $(\xi=1)$ the stiffness is small and the flexibility is big, so that the systems such as computers are not able to detect their value and fail. The governing equations for these two methods is expressed in Eq. (1) and (2), in which $\left(k_{S S}=k_{S^{-}} k_{C}\right)$ is the survived-stiffness, $\left(f_{S F}=f_{S}+f_{C}\right)$ is the survived-flexibility, $\left(k_{S}\right)$ is the system-stiffness, $\left(f_{S}\right)$ is the system flexibility, $\left(k_{C}\right)$ is the change-stiffness, $\left(f_{C}\right)$ is the change-flexibility, $(F)$ is the applied load and ( $\Psi$ ) is the resultant system displacement. In conventional methods the $\left(k_{S S}\right)$ and $\left(f_{S F}\right)$ and one of $(F)$ or $(\Psi)$ are assumed to be known and the other is the result of analysis. The symbolic Eq. (1) and (2) are representative of all conventional differential and integral equations:

$k_{S S} \psi=F \rightarrow F / \psi=k_{S S}$

$f_{S F} F=\psi \rightarrow F / \psi=1 / f_{S F}$

$k_{S S}=1 / f_{S F}$

Computation of the parameters that are assumed to be known and the result of analysis introduce epistemic uncertainty into the work. This is the main shortcoming of all conventional methods of analysis in different branches of human knowledge. This shortcoming is removed, in the change of state philosophy (Ranjbaran et al., 2020a), as follows. The first step was deletion of $(F)$ and $(\Psi)$, from the conventional equations, as in Eq. (3). Then, in view of Eq. (3), the product of equalities $\left(k_{S S}=1 / f_{S F}\right)$ for the changed state and $\left(1 / k_{S}=f_{S}\right)$ for the intact state, as shown in Fig. 3, is expressed in Equation (4):

$$
\begin{aligned}
& \left(k_{S S}=\frac{1}{f_{S F}}\right) \times\left(\frac{1}{k_{S}}=f_{S}\right)=\left(\frac{k_{S S}}{k_{S}}=\frac{f_{S}}{f_{S F}}\right) \\
& \left(k_{C}\right) \&\left(f_{C}\right)=?
\end{aligned}
$$

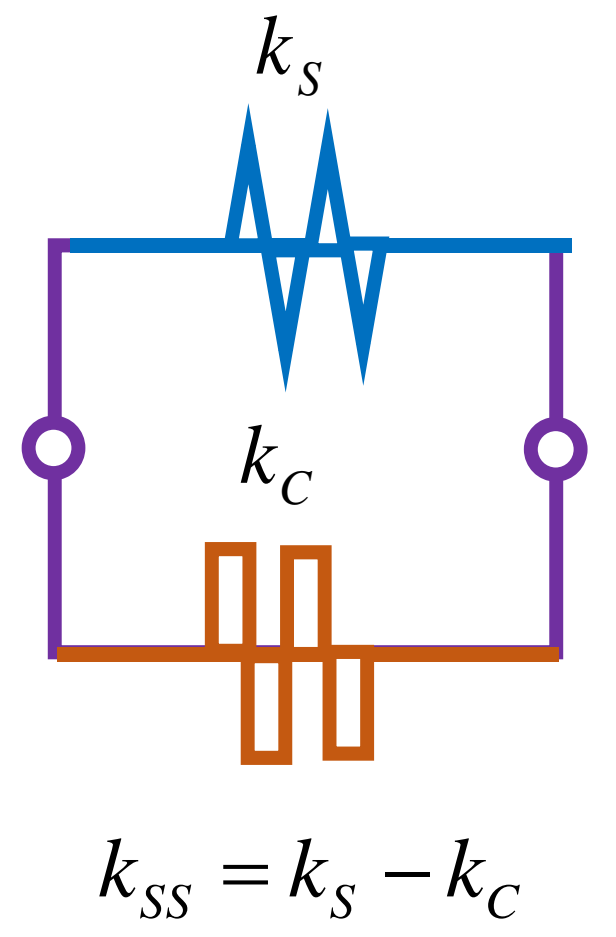

Fig. 1: Spring-model for stiffness method 


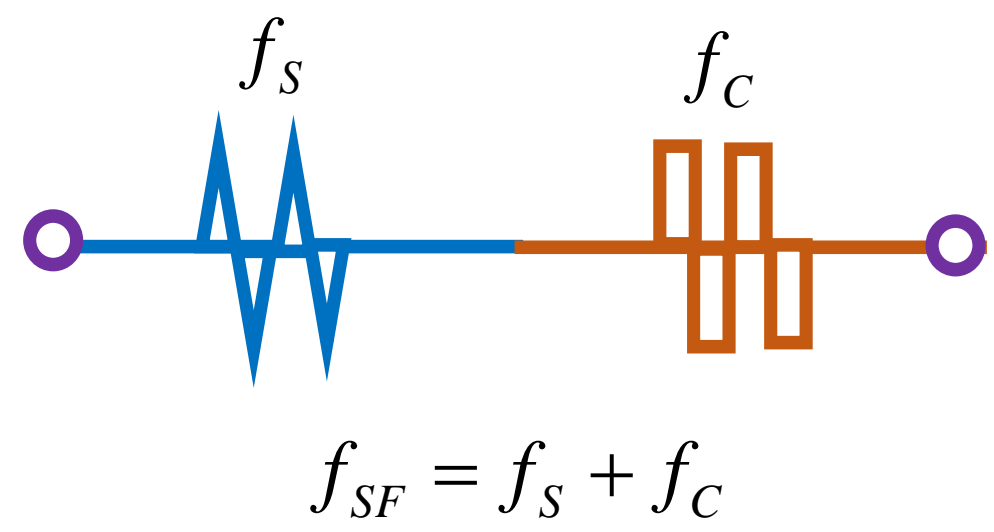

Fig. 2: Spring-model for flexibility method

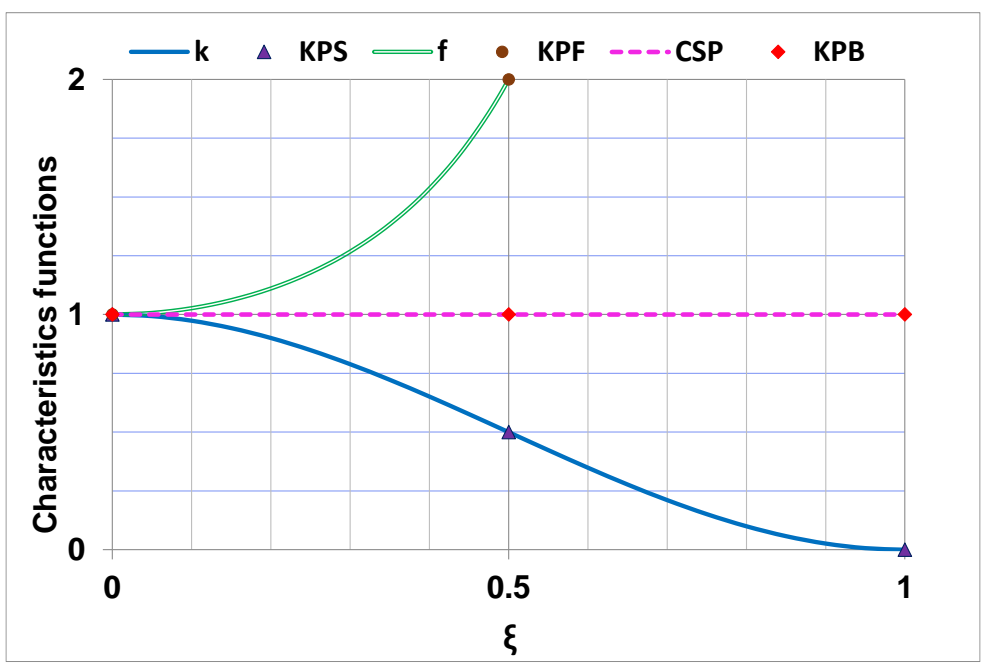

Fig. 3: Change of state philosophy basic equation

Equation (4) is rearranged to obtain the $\left(k_{S S}\right)$ and $\left(k_{C}\right)$, in terms of the other parameters, in Eq. (5):

$$
\begin{aligned}
& k_{S S}=\frac{f_{S} \times k_{S}}{f_{S}+f_{C}}=\frac{f_{S}}{f_{S}+f_{C}} \times k_{S}=S_{R} \times k_{S} \\
& k_{C}=k_{S}-k_{S S}=\frac{f_{C}}{f_{S}+f_{C}} \times k_{S}=F_{R} \times k_{S}
\end{aligned}
$$

in which the phenomenon functions (collection of the failure function $\left(F_{R}\right)$ and the survive function $\left(S_{R}\right)$ ) are defined in Eq. (6):

$$
F_{R}=\frac{f_{C}}{f_{S}+f_{C}} \in\left[\begin{array}{ll}
0 & 1
\end{array}\right] S_{R}=\frac{f_{S}}{f_{S}+f_{C}} \in\left[\begin{array}{ll}
1 & 0
\end{array}\right]
$$

Consideration of the fact that the dimensionless phenomenon functions are defined in a unit interval, introduces a down to earth method for human knowledge. Therefore the methods of analyzes based on these functions are free of common problems, such as singularity, instability and etc., that are available in the conventional methods in human knowledge. Consequently the authors decided to continue the investigation via looking for the correct and soft definition of the $\left(f_{C}\right)$ and other unknown functions.

The proposed form of phenomenon functions in Eq. (6) are defined in terms of the $\left(k_{C}\right)$ and the $\left(f_{C}\right)$, which are unknown to this end. The investigation for explicit definition of these functions is continued in the next paragraph via definition and construction of the so called state functions.

Development of functionals $\left(S_{R}\right.$ and $\left.F_{R}\right)$ in terms of two functions $\left(f_{S}\right.$ and $\left.f_{C}\right)$ is not possible. Then the phenomenon functions are customized for $\left(k_{S}=f_{S}=1\right)$ to define the destination function $(D)$, the origin function 
$(O)$ (which are collectively called the state functions) and the state Ratio $(R)$ in Eq. (7). This is an artifice to define functions $(D \& O)$ in terms of only one variable $(R)$ :

$$
F_{R} \Rightarrow D S_{R} \Rightarrow O f_{C} \Rightarrow R
$$

Consequently the $(D \& O)$ are defined in terms of the $(R)$ in Equation (8):

$D=\frac{R}{1+R} O=\frac{1}{1+R} R=\frac{D}{O}$

The state functions may be considered as the solution of the boundary value problems as expressed in Equation (9) and shown in Fig. 4, where ( $\mathrm{min}$ ) denotes minimum and (max) denotes maximum:

$$
D=\left\{\begin{array}{ll}
\min =0 & @ R=0 \\
\max =1 & @ R=\infty
\end{array} O= \begin{cases}\max =1 & @ R=0 \\
\min =0 & @ R=\infty\end{cases}\right.
$$

The state ratio, with the far end in the infinity (Fig. 4), is not a good working parameter. Moreover, this ratio is itself a function, so it is not wise to be used as an independent variable. Therefore, the state variable $\xi \in\left[\begin{array}{ll}0 & 1\end{array}\right]$ with a zero value $(\xi=0)$ at the origin and a unit value ( $\xi$ $=1)$ at the destination is defined. In term of the state variable, the boundary value problems in $\mathrm{Eq}$. (9) is rewritten as in Eq. (10):

$$
D=\left\{\begin{array}{ll}
\min =0 & @ \xi=0 \\
\max =1 & @ \xi=1
\end{array} O= \begin{cases}\max =1 & @ \xi=0 \\
\min =0 & @ \xi=1\end{cases}\right.
$$

Investigation for construction of solution for boundary value problems in Eq. (10), led the authors to make use of their experience in structural mechanics, finite element method, mathematics and their extensive research. The results are the state functions as defined in Eq. (11) and shown in Fig. 5 (Ranjbaran et al., 2020a):

$$
\begin{aligned}
& D=0.25\left(2-1+6 \xi^{2}-4 \xi^{3}-\cos \pi \xi\right) \\
& O=0.25\left(2+1-6 \xi^{2}+4 \xi^{3}+\cos \pi \xi\right)
\end{aligned}
$$

Equation (11) is an average of polynomial and trigonometric functions as defined in Eq. (12):

$$
\begin{aligned}
& D=0.25\left(0+6 \xi^{2}-4 \xi^{3}\right)+0.25(1-\cos \pi \xi) \\
& O=0.25\left(2-6 \xi^{2}+4 \xi^{3}\right)+0.25(1+\cos \pi \xi)
\end{aligned}
$$

The authors invite the readers from all over the world to propose new functions for the state functions and report to them. The authors cordially appreciates their efforts.

Via the definition of the survived stiffness $\left(k_{S S}\right)$ and the survived flexibility $\left(f_{S F}\right)$ and study of the equations for computation of crack compliance in fracture mechanics where cracking is considered as the change (Anderson, 2005), the authors detected a fact that, the $\left(f_{C}\right)$ is directly proportional to the $\left(k_{S}\right)$ ! This detection is called "the Persian Principle of Change $(P P C)$ ". In view of this principle the $\left(f_{C}\right)$ is defined in Eq. (13):

$f_{C} / R=k_{S} / 1 \rightarrow f_{C}=k_{S} R \rightarrow f_{C}=k_{S} D / O$

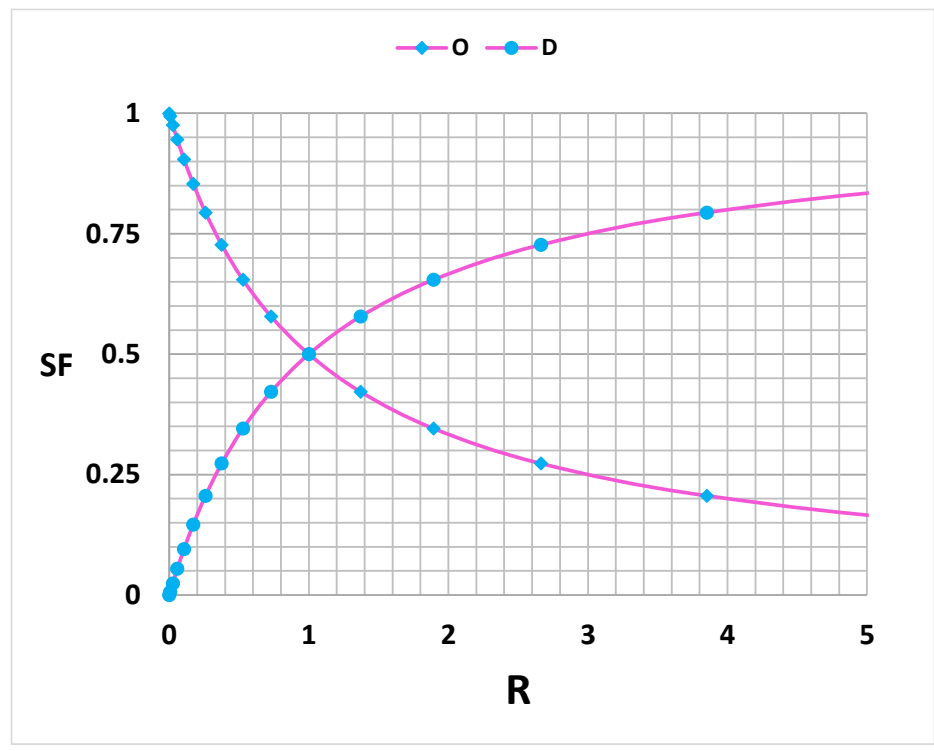

Fig. 4: State functions versus the state ratio 


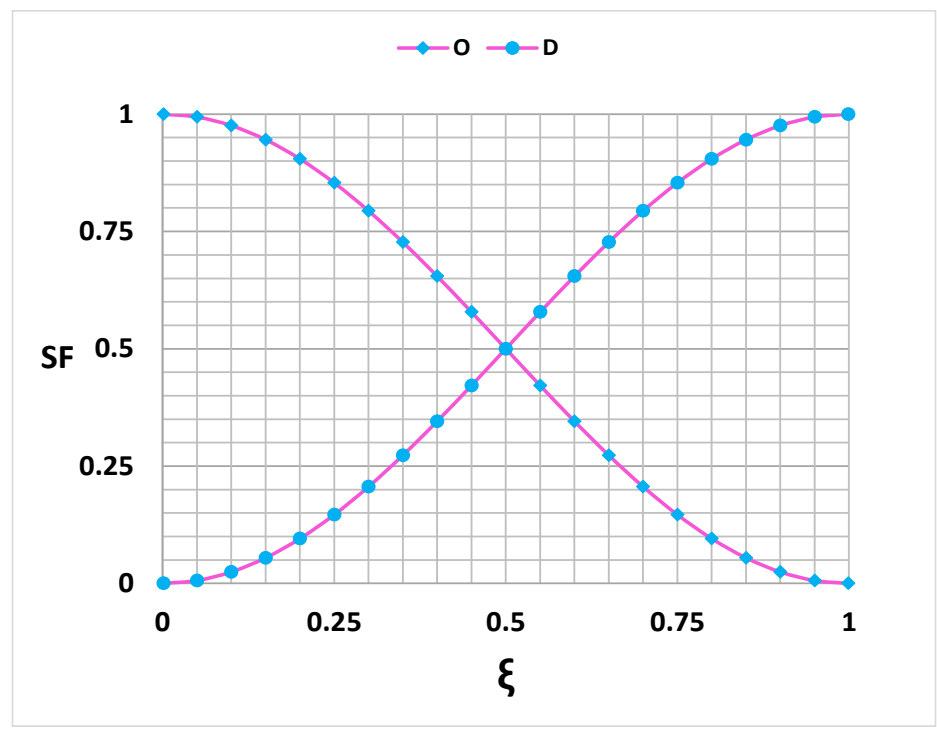

Fig. 5: State functions versus the state variable

Note that Eq. (13) is an alternative for the whole fracture mechanics. Substitution of Eq. (13) into Eq. (6) concluded in the general definition for the phenomenon functions in Eq. (14):

$$
F_{R}=\frac{k_{S}^{2} D}{O+k_{S}^{2} D} S_{R}=\frac{O}{O+k_{S}^{2} D}
$$

The $\left(k_{S}\right)$ is not explicitly known and so it is not a feasible working parameter. Therefore Equation (14) is rewritten in a unified form as in Eq. (15), in terms of the positive control parameters $\left(a_{M}\right)$ and $(b)$ (Ranjbaran et al., 2020a). The control parameters are to be determined from calibration of reliable data:

$$
F_{R}=\frac{a_{M} D^{b}}{O^{b}+a_{M} D^{b}} S_{R}=\frac{O^{b}}{O^{b}+a_{M} D^{b}}
$$

To this end the proposed formulation is mathematically in an abstract form, so it is a universal one in the sense that it is independent of geometrical and material properties and the changing agent. Therefore, it applies to all natural phenomena!

\section{Persian Curves}

As demonstrated in previous sections, the proposed formulation, were derived based on logical reasoning and concise mathematical logics. There was no need for construction and solution of differential and/or integral equations, which is the paramount basis of the conventional methods of analysis in human knowledge. Therefore the proposed formulation is free of epistemic uncertainty, because it is based on obvious and certain basis, for example the definition of flexibility as inverse of stiffness in Eq. (3).

For a given phenomenon, the lifetime is truncated at a workable interval $\left(\lambda \in\left[\lambda_{o} \lambda_{T}\right]\right)$ and is mapped onto the state variable in Eq. (16), where $\left(\lambda_{o}\right)$ is the origin point $(O)$ and $\left(\lambda_{T}\right)$ is the end point $(T)$ of the lifetime:

$$
\lambda=(1-\xi) \lambda_{o}+(\xi) \lambda_{T} \quad \xi=\left(\lambda-\lambda_{o}\right) /\left(\lambda_{T}-\lambda_{o}\right)
$$

As functions of the lifetime, the $\left(F_{R}\right)$ is renamed as Persian-Fasa-curve $\left(P_{F}\right)$ and the $\left(S_{R}\right)$ is renamed as Persian-Shiraz-curve $\left(P_{S}\right)$ and the two collectively called the Persian-curves $\left(P_{C}\right)$. In comply with vocabulary of human knowledge, the $\left(P_{S}\right)$ is the unified equation for the capacity and reliability and the $\left(P_{F}\right)$ is the unified equation for the probability and fragility. The reliable (capacity and reliability) and the reliable (probability and fragility) data are managed in decreasing and increasing order respectively. For a reliable data, $\left(P_{S}\right)$ for increasing data and $\left(P_{F}\right)$ for decreasing data, is defined as the Persian-curves $\left(P_{C}\right)$ in Eq. (17), in which $\left(P_{O}\right)$ is the ordinate of the start point $(O)$ and $\left(P_{T}\right)$ is the ordinate of the end point $(T)$. Note that the points $(O)$ and $(T)$ are the necessary and sufficient points for construction of Eq. (16) and (17). Note that insertion of $\left(P_{O}=1\right.$ and $\left.P_{T}=0\right)$ and $\left(P_{O}=0\right.$ and $\left.P_{T}=1\right)$ into Eq. (17) conclude into $\left(F_{R}\right)$ and $\left(S_{R}\right)$ respectively as in Eq. (15):

$$
P_{C}=\left(P_{O} O^{b}+P_{T} a_{M} D^{b}\right) /\left(O^{b}+a_{M} D^{b}\right)
$$


Moreover, in comply with the common practice in stochastic analysis the (probability) density distribution, here called the Persian-Zahedan-curve $\left(P_{Z}\right)$, is defined as the derivative of the phenomenon functions with respect to the state variable $(\xi)$, in Eq. (18), in which $\left(F_{R}^{(1)} S_{R}^{(1)}\right.$ and $\left.D^{(1)}\right)$ are the derivatives of $\left(F_{R}, S_{R}\right.$ and $\left.D\right)$ with respect to the $(\xi)$ respectively. Note that, in spite of the paramount role of the probability density in conventional probability theory, in the $(C S P)$ it has no permanent role and is only used for comparison with the conventional one:

$$
F_{R}^{(1)}=+P_{Z} S_{R}^{(1)}=-P_{Z} P_{Z}=\frac{b a_{M} D^{b-1} O^{b-1} D^{(1)}}{\left(O^{b}+a_{M} D^{b}\right)^{2}}
$$

For a reliable decreasing data as shown in Fig. 6 and for a reliable increasing data as shown in Fig. 7, the positive control parameters $\left(a_{M}\right)$ and $(b)$ are obtained, in terms of the coordinates of the Key-Points (KPS), in Eq. (19), see the Appendix:

$$
a_{N}=\frac{P_{N}-P_{O}}{P_{T}-P_{N}} a_{M}=\frac{P_{M}-P_{O}}{P_{T}-P_{M}} b=\frac{\log \left(a_{N} / a_{M}\right)}{\log \left(D_{N} / O_{N}\right)}
$$

The Key Points (KPS) are defined as the origin point $(O)$, the middle point $(M)$, the end point $(T)$ and the next point $(N)$ (a point between the other three), defined in Eq. (20) and shown in Figs. 6 and 7, for decreasing data and increasing data respectively:

$$
\begin{aligned}
& O\left(0.00, P_{o}\right) N\left(\xi_{N}, P_{N}\right) \\
& M\left(0.50, P_{M}\right) T\left(1.00, P_{T}\right)
\end{aligned}
$$

The $(O)$ and $(T)$ points are used for mapping in Eq. (16) and $(N)$ and $(M)$ are used for determination of $\left(a_{M}\right)$ and $(b)$ in Eq. (19). Finally, via logical reasoning, a unified equation for capacity (design) and fragility (assessment) curve is proposed as follows. Extensive research of the author's team (Ranjbaran et al., 2020a) concluded into the fact that the Persian curve for complete failure is defined in Eq. (21) (We looked for reliable capacity data in different codes, theses, dissertations, papers and reports (Ranjbaran et al., 2020a). Analysis of these data shown that the values of $\left(a_{M}\right.$ $=2$ and $b=1)$ satisfied all requirements. Then substitution of the ( $a_{M}=2$ and $\left.b=1\right)$ into Eq. (17) and (18) concluded in Eq. (21)), where $\left(P_{S U}\right)$ is unified capacity, $\left(P_{F U}\right)$ is unified fragility and $\left(P_{Z U}\right)$ is unified density. As shown, fragility is equal to $1 \mathrm{~min}$ capacity and vice versa. Moreover the horizontal axis, which is the Peak Ground Acceleration $(P G A)$ as a measure index $(I M \in[0,3])$ in fragility curve is replaced by the relative slenderness $\left(\lambda=(L / r) \sqrt{F_{y} / \pi^{2} E} \in[0,3]\right)$ in capacity analysis, in which $(L)$ is effective length, $(r)$ is radius of gyration, $\left(F_{y}\right)$ is yield limit and $(E)$ is working (elastic) modulus:

$$
\begin{gathered}
P_{F U}=\frac{1.8 D}{1+D} P_{S U}=\frac{1-0.8 D}{1+D} \\
P_{Z U}=\frac{2 D^{(1)}}{(1+D)^{2}} a_{M}=2 b=1
\end{gathered}
$$

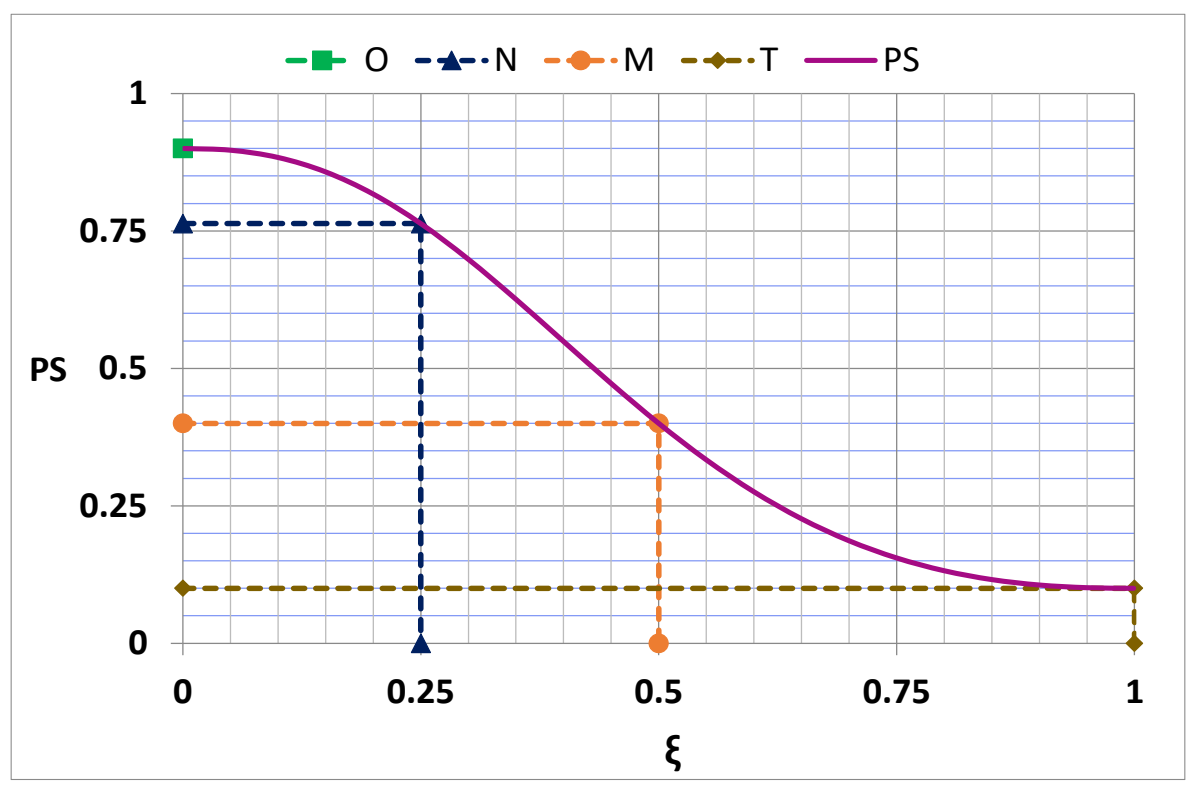

Fig. 6: Key points on Persian-shiraz-curve 


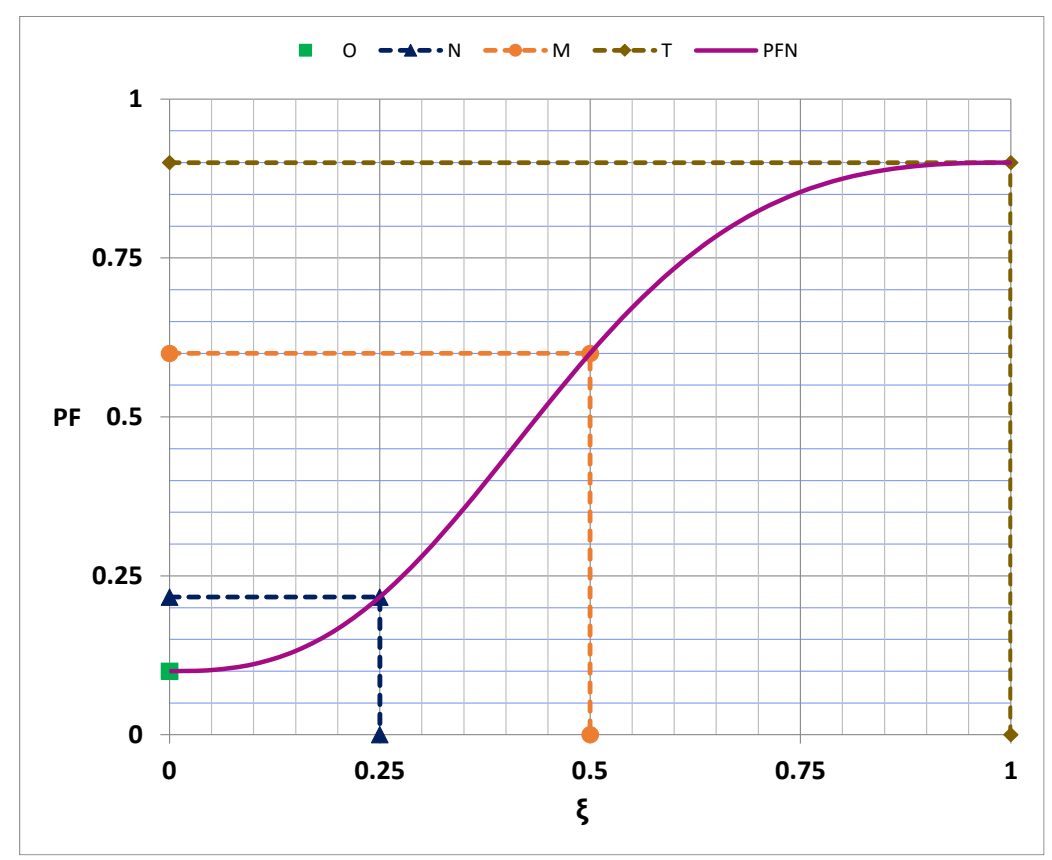

Fig. 7: Key points on Persian-Fasa-curve

Moreover the key point ordinate on unified Persian curves are defined in Eq. (22). The values recorded in Eq. (22) are the corresponding parameters for $(O, N$, $M$ and $T$ ) which are computed from Eq. (16) and (21) for completeness:

$\begin{array}{ccccc}P C & O & N & M & T \\ \lambda & 0.000 & 0.750 & 1.500 & 3.000 \\ \xi & 0.000 & 0.250 & 0.500 & 1.000 \\ P_{F U} & 0.000 & 0.237 & 0.600 & 0.900 \\ P_{S U} & 1.000 & 0.763 & 0.400 & 0.100 \\ P_{Z U} & 0.000 & 1.686 & 1.364 & 0.000\end{array}$

Persian curve is managed as a bridge between the abstract mathematical concepts and the real world. Therefore it is applied for stability analysis of glass structures in the following section. Perhaps these are the most beautiful (simple, explicit and accurate) equations in the literature. Here is the end of the proposed logical formulation. Note that the question $\left(\left(k_{C}\right)\right.$ and $\left(f_{C}\right)=$ ?) in Equation (4) is logically answered.

\section{Persian Curve Interpretation}

For the case of lifetime as value of real world data, the Persian Curves are interpreted as follows. The value of $\left(P_{S}\right)$ for a data point $\left(\lambda_{A}\right)$ denotes the ratio of number of data $\left(n_{S}\right)$ greater than $\left(\lambda_{A}\right)$ over the total number of data $\left(n_{t}\right)$. It is a weight for data in the upper region. Similarly, the value of $\left(P_{F}\right)$ for a data point $\left(\lambda_{A}\right)$ denotes the ratio of number of data $\left(n_{F}\right)$ less than $\left(\lambda_{A}\right)$ over the total number of data $\left(n_{t}\right)$. It is a weight for data in the lower region.

For the case of lifetime as a parameter of the system (such as relative slenderness ratio of structures), the Persian Curves are interpreted as follows. The value of $\left(P_{S}\right)$ for a data point $\left(\lambda_{A}\right)$ denotes efficiency of the system, while the system-deficiency is denoted by the value of $\left(P_{F}\right)$.

\section{Persian-Curves for Glass Structure Capacity}

The proposed Persian-curves are used in load bearing capacity of glass structures as follows. In comply with the literature the verification of the work is done via comparison of the results with that of the others in the following examples. As explained in previous sections, the unified Persian curves from Equation (21) is to be used for determination of the ultimate strength of structural members. The capacity curve (PSU), the fragility curve (PFU) and the density distribution (PZU) for glass members are compared with the results of experiments in the following examples, where $(\xi=\lambda / 3)$. The data is scanned from the addressed references.

\section{Example 1}

Feldmann and Langosch (2010), conducted tests for buckling capacity of glass planes under axial 
loading. The buckling loads of column specimens without eccentricity (FELD), is compared with the unified Persian curves in Fig. 8. Close agreement of the results verified the work.

\section{Example 2}

Amadio and Bedon (2012) focused on the load carrying behavior of in plane compressed laminated glass elements. They proposed some analytical formulation and verified their results via comparison of the results with the results of test selected from open literature. Their numerical and experimental results, for lateral torsional buckling of beams in compression (AMAD) is scanned and compared with the unified Persian curves in Fig. 9. Excellent agreement of the results is a flag for reliability of the unified Persian curves.

\section{Example 3}

Monolithic and laminated glass elements, are typically brittle and slender, thus frequently subjected to buckling phenomena. Amadio and Bedon (2013) focused on the load carrying behavior of 2-layyer and 3-layyer simply supported laminated glass panels subjected to in-plane shear load. They verified their work via comparison with the numerical analysis and with the experimental results. The numerical and the test results (AMAD) for a 2-layyer laminated glass panel under in plane shear load is compared with the unified Persian curves in Fig. 10. The results expressed the validity of Persian curves for ultimate strength analysis of laminated panels under in plane shear load.

\section{Example 4}

Structural glass is frequently used in modern buildings. The verification of load-carrying elements composed of traditional materials, analytical procedures and consolidated verification methods are available in standards, this is not the case for glass. A Eurocode based approach is proposed for the buckling verification of glass columns and beams in (Bedon and Amadio, 2015). They used numerical and experimental results for verification of their proposed method. The experimental and numerical results for flexural torsional buckling load for monolithic and laminated glass beams (BEDON) is compared with the unified Persian curves in Fig. 11. The feasibility of the unified Persian curve as a design curve for glass structure is apparent from this example.

\section{Example 5}

Pešek and Melcher (2018), conducted experimental research of stability behavior of laminated structural glass beams. The purpose of their research was evaluation of lateral-torsional buckling resistance and actual behavior of beams due to absence of standards for design of glass load bearing structures. Their experimental results (PESEK) is compared with the unified Persian curves in Fig. 12.

At a point in the loaded system the released Energy Density (ER) over the available Energy Density (EA) is equal to $(\mathrm{R}=\mathrm{D} / \mathrm{O})$ (Ranjbaran et al., 2020c). Then at $(\xi=0.5)$ the $(\mathrm{ER}=\mathrm{EA})$ and the system become unstable. That is a reason for better agreement between the theory and experiments for $(\xi \geq 0.5)$.

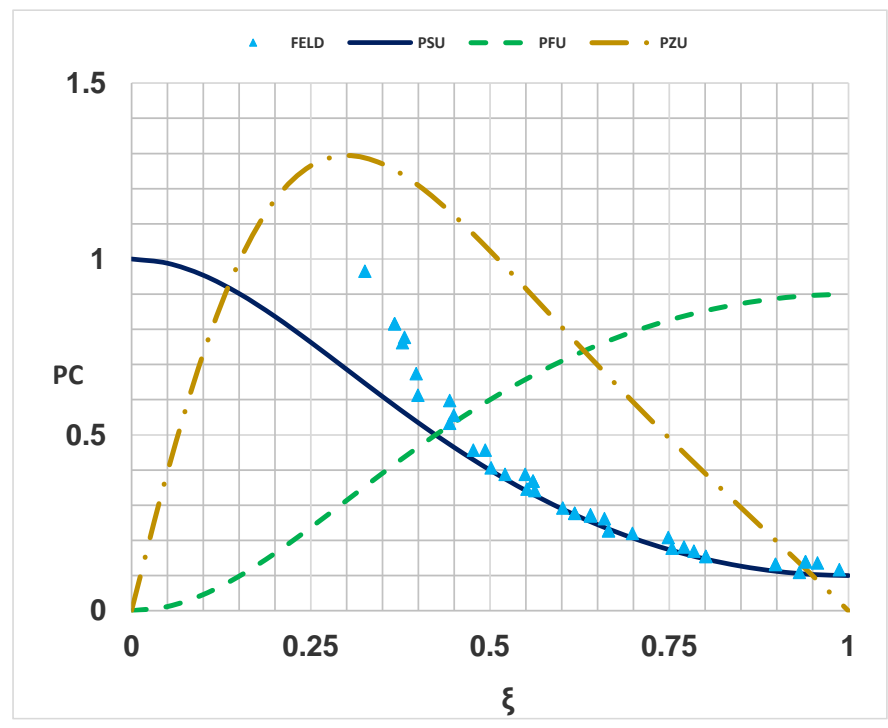

Fig. 8: Comparison of Persian curve and monolithic glass column test results 


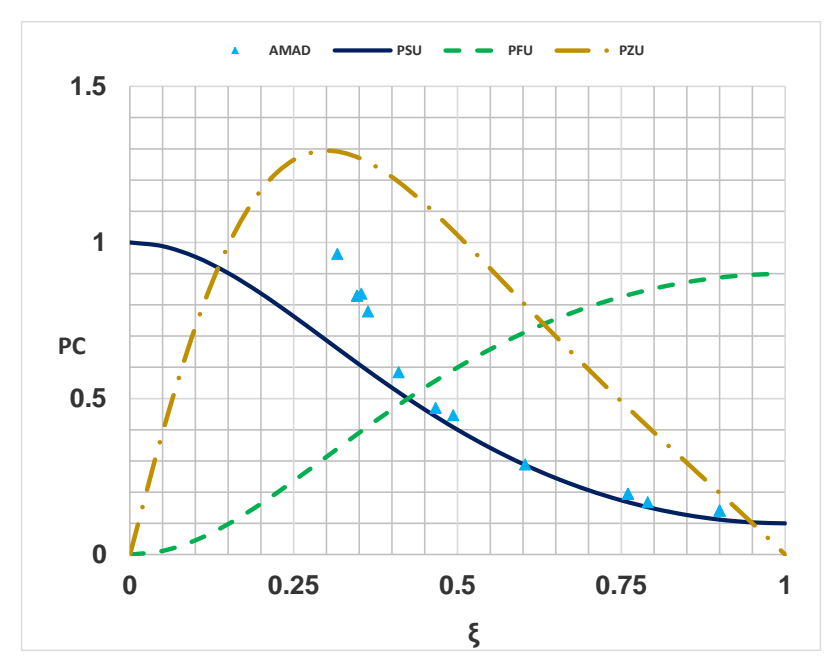

Fig. 9: Comparison of Persian curves with the numerical and experimental lateral torsional buckling of glass beams

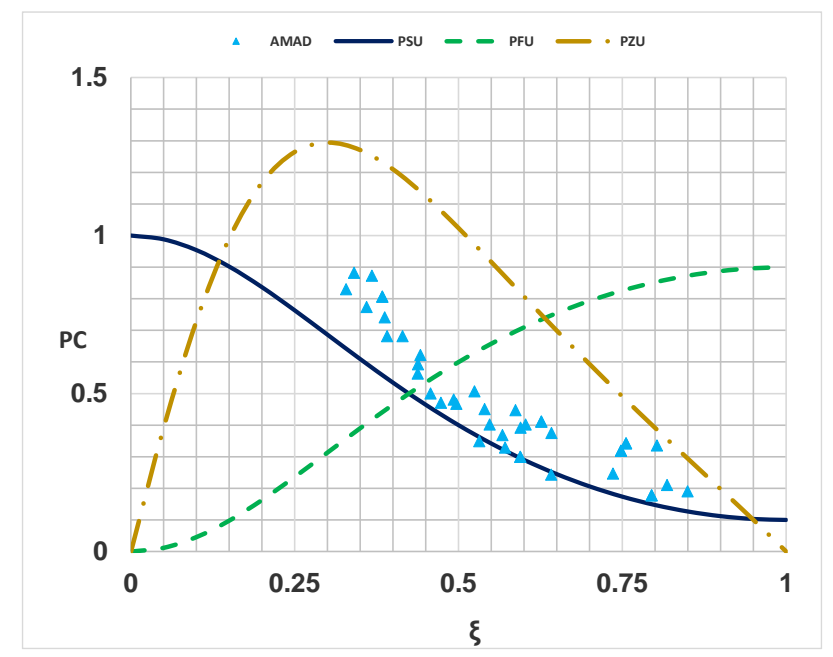

Fig. 10: Comparison of Persian curve with experimental buckling load of laminated glass panels under in plane shear load

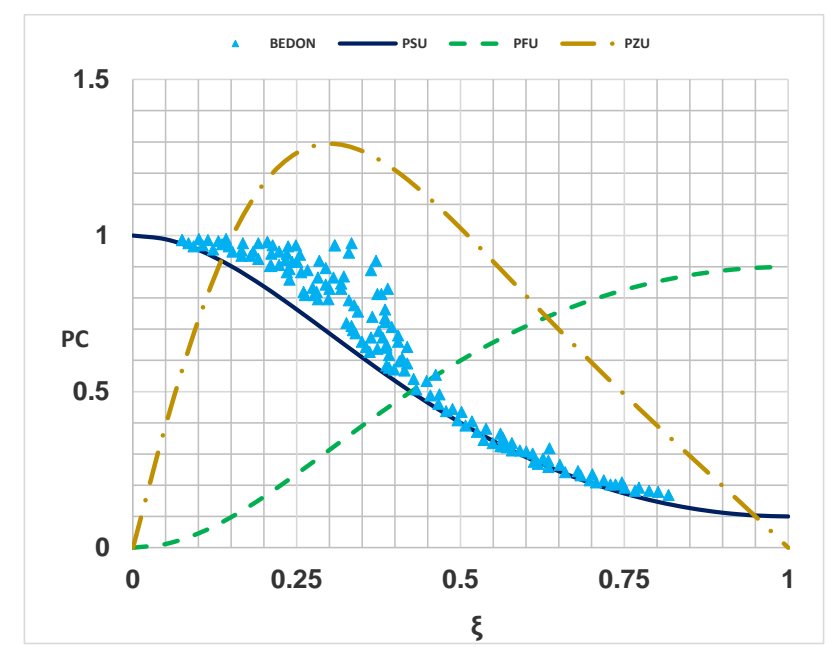

Fig. 11: Comparison of Persian curve with numerical and experimental flexural torsional buckling load of laminated glass beams 


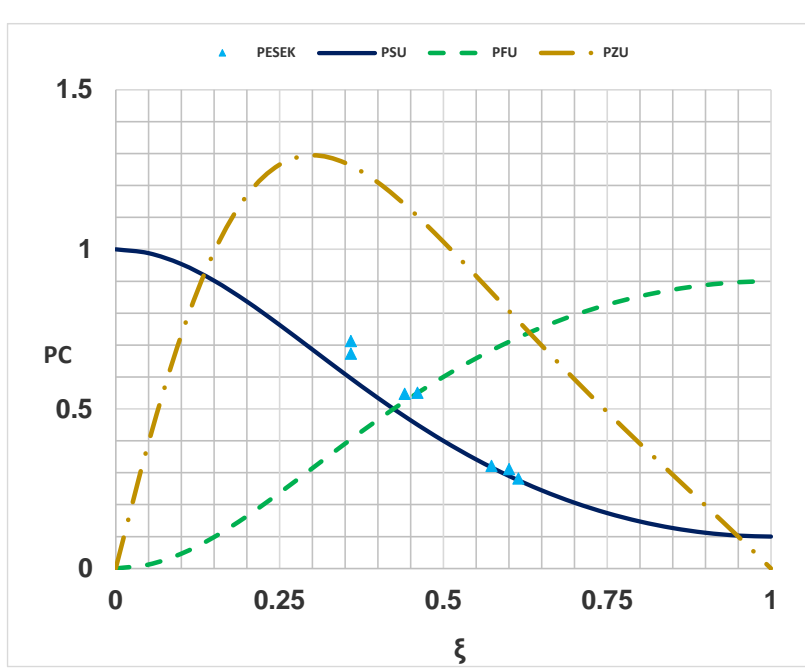

Fig. 12: Comparison of Persian curve with the experimental lateral torsional buckling load of laminated glass beams

\section{Conclusion}

The following conclusions are obtained from the present study.

The author's research team conducted an intensive research in the past two decades on analysis of natural phenomena. Via logical reasoning and concise mathematics they proposed the so called change of state philosophy which is expressed in the Persian curve. The Persian curve is then used to derive the universal capacity design curve for all structures. The proposed method is simple, explicit and exact and needs no nonlinear analysis. The validity of the work is verified via concise mathematics and comparison of the results with the results of experiments for stability analysis of structural glass members.

\section{Acknowledgment}

Thanks to all members of our family, specially Zahra, who provided a calm state and condition, at the time of Corona at home and encouraged writing of the paper. Note that the names of Persian curves were selected as the names of cities, Fasa, Shiraz and Zahedan in Iran, where the authors birthed, grown, educated and worked.

\section{Author's Contributions}

Abdolrasoul Ranjbaran: Designed and contributed in writing the first draft and later corrections of the manuscript.

Mohammad Ranjbaran: Contributed in literature review, derivation of equations and engaged in the research team discussions.

Fatema Ranjbaran: Contributed in numerical analysis and engaged in the research team discussions.

\section{Ethics}

This article is original and contains unpublished material. The corresponding author confirms that all of the other authors have read and approved the manuscript and no ethical issues involved with declaration of no conflict of interest.

\section{Appendix}

\section{Determination of Control Parameters}

Close insight into Eq. (11) and (17) concluded into the selection of the middle point $(M)$ as an important key point due to the property in Eq. (23):

$D_{M}=0.5 O_{M}=0.5 D_{M}=O_{M}$

Substitution of Eq. (23) into Eq. (17) concluded into a simple definition for the $\left(a_{M}\right)$ in Eq. (24):

$P_{M}=\frac{P_{O} O_{M}^{b}+P_{T} a_{M} D_{M}^{b}}{O_{M}^{b}+a_{M} D_{M}^{b}} \Rightarrow a_{M}=\frac{P_{M}-P_{O}}{P_{T}-P_{M}}$

Moreover the control parameter $(b)$ is determined by substitution of Eq. (24) and coordinates of the next key point $(N)$ into Eq. (17), as in Eq. (25):

$$
\begin{aligned}
& P_{N}=\frac{P_{O} O_{N}^{b}+P_{T} a_{M} D_{N}^{b}}{O_{N}^{b}+a_{M} D_{N}^{b}} \Rightarrow\left(\frac{D_{N}}{O_{N}}\right)^{b}=\frac{P_{N}-P_{O}}{\left(P_{T}-P_{N}\right) a_{M}} \\
& a_{N}=\frac{P_{N}-P_{O}}{P_{T}-P_{N}} \Rightarrow b=\frac{\log \left(a_{N} / a_{M}\right)}{\log \left(D_{N} / O_{N}\right)}
\end{aligned}
$$


Since the direction of ( $T$ to $C$ ) and ( $C$ to $O$ ), for a point $(C)$ on both of the increasing and decreasing data, is the same, then the control parameters $\left(a_{M}\right.$ and $\left.b\right)$ are always positive.

\section{References}

Amadio, C., \& Bedon, C. (2011). Buckling of laminated glass elements in compression. Journal of structural Engineering, 137(8), 803-810.

Amadio, C., \& Bedon, C. (2012). Buckling verification of laminated glass elements in compression. J Civ Eng Sci, 1(3), 90-101.

Amadio, C., \& Bedon, C. (2013). An equivalent thickness for buckling verification of laminated glass panels under in-plane shear loads. Journal of Civil Engineering and Science, 2(3), 108-123.

Amirian, P., \& Ranjbaran, A. (2020). Studying the Effect of Fundamental Structural Period on the Seismic Fragility Curves of Two-Span Integral Concrete Box Girder Bridges. Iranian Journal of Science and Technology, Transactions of Civil Engineering, 44(1), 11-26.

Anderson, T. L. (2005). Fracture mechanics: fundamentals and applications. Taylor and Francis Group LLC, USA, 2005.

Baharvand, A., \& Ranjbaran, A. (2020a). Seismic Fragility Functions Grounded on State-Based Philosophy: Application to Low to Midrise Steel Frame Buildings. KSCE Journal of Civil Engineering, 24: 1787-1798.

Baharvand, A., \& Ranjbaran, A. (2020b). A new method for developing seismic collapse fragility curves grounded on state-based philosophy. International Journal of Steel Structures, 20: 583-599.

Bedon, C. (2019). Issues on the vibration analysis of inservice laminated glass structures: analytical, experimental and numerical investigations on delaminated beams. Applied Sciences, 9(18), 3928.

Bedon, C., \& Amadio, C. (2015). Design buckling curves for glass columns and beams. Proceedings of the Institution of Civil Engineers-Structures and Buildings, 168(7), 514-526.

Bedon, C., \& Amadio, C. (2016). A unified approach for the shear buckling design of structural glass walls with non-ideal restraints. Am. J. Eng. Applied Sci, 9, 64-78.

Bedon, C., \& Amadio, C. (2017). Comparative assessment of analytical models for the ULS resistance verification of structural glass elements under variable loads. American Journal of Engineering and Applied Sciences, 10(1): 229-242.

Bedon, C., \& Amadio, C. (2018). A linear formulation for the ULS design of glass elements under combined loads: application to IGUs. Glass Structures \& Engineering, 3(2), 289-301.
Bedon, C., Amadio, C., \& Noé, S. (2019). Safety issues in the seismic design of secondary frameless glass structures. Safety, 5(4), 80 (1-30).

Costa MSLM. (2015). Modeling of the structural behavior of laminated glass beams. MSc. thesis, Department of Civil Engineering, University of Lisbon, Portugal 2015.

Feldmann, M., \& Langosch, K. (2010). Buckling resistance and buckling curves of pane-like glass columns with monolithic sections of heat strengthened and tempered glass. In Challenging Glass Conference Proceedings (Vol. 2, pp. 319-330).

Hosseini, S., Ranjbaran, A., \& Roosta, S. (2018). Progressive collapse of tall steel buildings designed with outrigger brace system. Ned University Journal of Research, 15(1): 1-14.

Koca, E. (2019). Modeling, design and tests of posttensioned glass t-beams. MSc thesis, Department of Civil Engineering, Middle East Technical University, Turkey.

Ouwerkerk, E. (2011). Glass columns: A fundamental study to slender glass columns assembled from rectangular monolithic flat glass plates under compression as a basis to design a structural glass column for a pavilion. MSc Thesis, Department of Civil Engineering, Delft University of Technology, Netherlands

Pešek, O., \& Melcher, J. (2018). Lateral-torsional buckling of laminated structural glass beams. Experimental, theoretical and numerical analysis. International Journal of Structural and Civil Engineering Research, 7(4): 323-330.

Porter, M. (2011). Aspects of structural design with glass. PhD dissertation, Balliol college and the department of Engineering Science, the University of Oxford, 2011, UK.

Ranjbaran, A., Ranjbaran, M., \& Ranjbaran, F. (2020a). Change of state philosophy \& Persian curves. LAP LAMBERT Academic Publishing, 225.

Ranjbaran, A., Ranjbaran, M., \& Ranjbaran, F. (2020b). Building probability functions by Persian curves. International Journal of Structural Glass and Advanced Materials Research, 2020; 4(1): 225-232.

Ranjbaran, A., Ranjbaran, M., \& Ranjbaran, F. (2020c). A reliable fracture mechanics. International Journal of Reliability, Risk and Safety: Theory and Application, 2020; 3(1): 1-15.

Ranjbaran, A., Ranjbaran, M., \& Baharvand, A. (2020d). A step toward development of generic fragility curves. Ned University Journal of Research, 17(3): 45-52. 
Ranjbaran, A. (2010). Analysis of cracked members the governing equations and exact solutions. Iranian Journal of Science and Technology Transaction B: Engineering, 34(B4): 407-417.

Ranjbaran, A. (2012a). Analysis of cracked members: free vibration, buckling, dynamic stability. Lap Lambert Academic Publishing Saarbrucken Germany. ISBN 978-3-659-208141-6.

Ranjbaran, A. (2012b). The dynamic stability analysis: application to beam-like structures. Lap Lambert Academic Publishing. ISBN 978-3-659-23467-5.

Ranjbaran, A. (2013). The finite element method for research: interesting and innovative ideas. Lap Lambert Academic Publishing Saarbrucken Germany. ISBN 978-3-659-32622-6.

Ranjbaran, A. (2014). Free-vibration analysis of stiffened frames. Journal of Engineering Mechanics, 140(9), 04014071.

Ranjbaran, A. (2015). Buckling analysis of stiffened frames. Ned University Journal of Research, 12(1), 29-41.

Ranjbaran, A. (2016). New generalized weight function for stress intensity factor. Ned University Journal of Research, 13(1), 33-42.

Ranjbaran, A., \& Ranjbaran, M. (2014). New finiteelement formulation for buckling analysis of cracked structures. Journal of Engineering Mechanics, 140(5), 04014014.

Ranjbaran, A., \& Ranjbaran, M. (2016). State functions: the milestone of fracture. Archive of Applied Mechanics, 86(7), 1311-1324.

Ranjbaran, A., \& Ranjbaran, M. (2017a). State-based buckling analysis of beam-like structures. Archive of Applied Mechanics, 87(9), 1555-1565.

Ranjbaran, A., \& Ranjbaran, M. (2017b). State based damage mechanics. NED University Journal of Research, 14(1), 13-26.

Ranjbaran, A., \& Ranjbaran, M. (2017c). Innovative theory for the compliance computation in rotors. Scientia Iranica, 24(4), 1779-1788.

Ranjbaran, A., \& Ranjbaran, M. (2018). State based method for ultimate strength analysis of stiffened panels. Ned University Journal of Research, 15(1), 39-49.

Ranjbaran, A., \& Rousta, H. (2013a). Interaction diagram for dynamic stability by Laplace transform. NED University Journal of Research, 10(1), 31-39.

Ranjbaran, A., \& Rousta, H. (2013b). Finite element analysis of cracked beams innovative weak form equations. NED University Journal of Research, 10(1), 39-47.

Ranjbaran, A., Hashemi, S., \& Ghaffarian, A. (2008). A new approach for buckling and vibration analysis of cracked column. International Journal of Engineering, Transactions A: Basics, 21(3): 225-230.
Ranjbaran, A., Rousta, H., \& Ranjbaran, M. (2013a). Dynamic stability of cracked columns; the stiffness reduction method. Scientia Iranica, 20(1), 57-64.

Ranjbaran, A., Rousta, H., Ranjbaran, M. O., Ranjbaran, M. A., Hashemi, M., \& Moravej, M. T. (2013b). A necessary modification for the finite element analysis of cracked members detection, construction and justification. Archive of Applied Mechanics, 83(7), 1087-1096.

Ranjbaran, A., Shokrzadeh, A. R., \& Khosravi, S. (2011). A new finite element analysis of free axial vibration of cracked bars. International Journal for Numerical Methods in Biomedical Engineering, 27(10), 1611-1621.

Santo, D., Mattei, S., \& Bedon, C. (2020). Elastic Critical Moment for the Lateral-Torsional Buckling (LTB) Analysis of Structural Glass Beams with Discrete Mechanical Lateral Restraints. Materials, 13(11), 2492.

\section{List of Symbols}

$\begin{array}{ll}a_{M}: & \text { Control parameter at } M \\ a_{N}: & \text { Control parameter at } N \\ A_{ \pm}: & \text {Sign parameter } \\ A_{ \pm}=-1: & \text { For decreasing data } \\ A_{ \pm}=+1: & \text { For increasing data } \\ b: & \text { Control parameter (power) } \\ C S P: & \text { Change of State Philosophy } \\ D: & \text { Destination function } \\ E: & \text { Initial modulus } \\ F: & \text { Force } \\ F_{y}: & \text { Yield limit } \\ f_{S}: & \text { System flexibility } \\ f_{C}: & \text { Change flexibility } \\ F_{S}: & \text { Dimensioned flexibility } \\ f_{S F}: & \text { Survived flexibility } \\ F_{R}: & \text { Failure function } \\ \left(F_{R} \text { and } S_{R}\right): & \text { Phenomenon functions } \\ f_{W}: & \text { Weibull probability density function } \\ F_{W}: & \text { Weibull cumulative distribution function } \\ \gamma: & \text { Recovery rate } \\ k_{S}: & \text { System stiffness } \\ k_{C}: & \text { Change stiffness } \\ k_{S S}: & \text { Survived stiffness } \\ K P F: & \text { Key points on Failure curve } \\ K P S: & \text { Key points on Survive curve } \\ K P S: & \text { Key points } \\ L: & \text { Effective length } \\ L B: & \text { Lower bound } \\ \lambda: & \text { Lifetime parameter } \\ \lambda=\frac{L}{r} \sqrt{\frac{F_{y}}{\pi^{2} E}:} & \text { Relative slenderness ratio } \\ \lambda: & \end{array}$


Abdolrasoul Ranjbaran et al. / International Journal of Structural Glass and Advanced Materials Research 2021, Volume 5: 1.13 DOI: 10.3844/sgamrsp.2021.1.13

$\begin{array}{llll}\lambda_{T}: & \text { Lifetime termination (end) } & P_{Z}: & \text { Persian-Distribution function } \\ M: & \text { Middle point } & P_{F}: & \text { Persian-Failure function } \\ N: & P_{S}: & P_{C}=\left(P_{F} \text { and } P_{S}\right): \text { Persian curves } \\ O: & r: & \text { Effective radius of gyration } \\ O: & \text { Origin (start) point } & R: & \text { State ratio } \\ P C: & \text { Origin function } & S_{R}: & \text { Survive function } \\ P_{O}: & \text { Persian curve (s) } & S_{F}=(D \text { and } O): \text { State functions } \\ P_{N}: & \text { Origin point ordinate } & T: & \text { Termination (end) point } \\ P_{M}: & \text { Next point ordinate } & U B: & \text { Upper bound } \\ P_{T}: & \text { Middle point ordinate } & \xi: & \text { State variable } \\ P_{F U}: & \text { End point ordinate } & \psi: & \text { Displacement } \\ P_{S U}: & \text { Unified Persian-failure function } & & \end{array}$

